\title{
Uma análise dos resultados dos diferentes tipos de escolas públicas no Sistema Permanente de Avaliação da Educação Básica do Ceará (Spaece)
}

\begin{abstract}
An analysis of the results of different types of public schools in the Permanent Evaluation System for Basic Education in Ceará (Spaece) Un análisis de los resultados de diferentes tipos de escuelas públicas en el Sistema de Evaluación Permanente de Educación Básica en Ceará (Spaece)
\end{abstract}

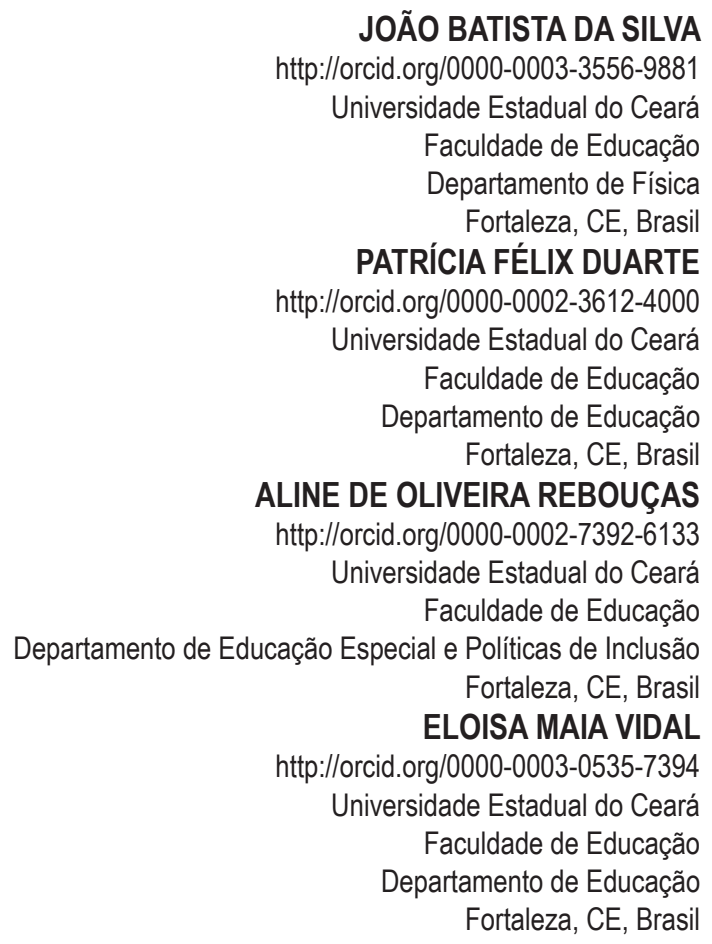

\begin{abstract}
Resumo: As avaliações de larga escala adquiriram protagonismo na política educacional a ponto de servir para estabelecer padrões associados à qualidade da educação. No artigo, são analisados os resultados de desempenho de alunos da $3^{a}$ série de 155 escolas públicas de ensino médio da cidade de Fortaleza, obtidos no sistema estadual de avaliação de larga escala do Ceará, em 2019. As escolas foram organizadas em três clusters, e os dados foram tratados com uso de estatística descritiva. As escolas de educação profissional obtiveram melhor desempenho e, nelas, a carga horaria diária, a infraestrutura e outras variáveis extra e intraescolares são diferenciadas, o que pode influir na proficiência dos estudantes.
\end{abstract}

Palavras-chave: Tipos de escola; Spaece; Avaliação; Política educacional. 


\begin{abstract}
Large-scale assessments have got protagonism in educational policy to the point of basing establishment of standards related to the quality of education. In the paper, we analyze the performance results of 3 rd grade students from 155 public high schools in Fortaleza obtained in the state of Cearás large-scale evaluation system, in 2019. The schools were organized into three clusters, and the data were translated using descriptive statistics. Vocational education schools performed better, and among them, the daily workload, infrastructure, and other extra and intra-school variables are differentiated, which can influence students' proficiency.
\end{abstract}

Key words: Types of schools; Spaece, Evaluation; Educational policy.

Resumen: Las evaluaciones a gran escala se han vuelto prominentes en la politica educativa hasta el punto de servir para establecer estándares asociados a la calidad de la educación. En el artículo se analizan los resultados de desempeño de estudiantes de 3er grado de 155 escuelas secundarias públicas de Fortaleza, obtenidos en el sistema de evaluación a gran escala del estado de Ceará, en 2019. Las escuelas se han organizado en tres clusters, y los datos se han traducido mediante estadística descriptiva. Las escuelas de educación profesional obtuvieron mejores resultados y en ellas se diferencia la carga diaria de trabajo, la infraestructura y otras variables extra e intraescolares que pueden influir en la competencia de los estudiantes.

Palavras-chave: Tipos de escuelas; Spaece; Evaluación; Política educativa.

\title{
INTRODUÇÃO
}

O ensino médio é a última etapa da educação básica e tem, como algumas finalidades, a consolidação e aprofundamento dos conhecimentos adquiridos no ensino fundamental, a preparação básica para o trabalho e a cidadania, e a possibilidade de prosseguimento de estudos (BRASIL, 1996).

Todavia, os problemas relacionados à oferta e ao acesso ao ensino médio no sistema educacional brasileiro são históricos (CASAGRANDE; ALONSO, 2019). De acordo com Santos, Moraes e Albuquerque (2019), o ensino médio no Brasil apresenta, ao longo de sua história, uma diversidade de formas de oferta e "um histórico de divergências quanto às suas finalidades e, em paralelo, de reformas visando torná-lo contemporâneo às necessidades e projetos sociais e políticos de cada período" (SANTOS; MORAES; ALBUQUERQUE, 2019, p. 106).

O Ensino Médio nas escolas públicas estaduais cearenses, em especial na cidade de Fortaleza, é ofertado por uma heterogeneidade de instituições, que apresentam diferenças nas condições de infraestrutura, nas formas de acesso, na organização, no trabalho pedagógico, na carga horária, no currículo, entre outras. De acordo com dados da Secretaria da Educação do Ceará (Seduc), existem três tipos de escolas públicas de nível médio predominantes na capital cearense: Escolas de Ensino Médio Regular (ER); Escolas de Ensino Médio em Tempo Integral (EEMTI); e Escolas Estaduais de Educação Profissional (EEEP). 
As Escolas de Ensino Médio Regular, conforme Oliveira (2016), são aquelas que ofertam apenas as disciplinas básicas presentes na $\mathrm{LDB}$, totalizando 13 disciplinas, nas 3 áreas do conhecimento (Linguagens e Códigos, Ciências da Natureza e Matemática e Ciências Humanas), em apenas um turno (manhã, tarde ou noite). A carga horária dessas escolas é de, aproximadamente, 4 horas e 30 minutos por dia. Segundo Neto et al. (2016) esse tipo de escola concentra a maior parte das matrículas na rede estadual de ensino. Elas não possuem processo seletivo para a admissão de alunos, e algumas possuem oferta noturna; os alunos recebem merenda escolar, e seus diretores são escolhidos por processo seletivo sucedido de eleição pela comunidade escolar. Desse cluster, a exceção são as duas escolas militares que possuem um rigoroso processo seletivo para admissão de alunos, oferecem anos iniciais e finais do ensino fundamental, juntamente com o ensino médio e sua gestão conta com interferência da Secretaria de Segurança Pública do Estado.

Nas EEMTI, cuja oferta se inicia em 2016, de acordo com a Seduc, os alunos têm, em média, 45 horas-aula semanais e nove tempos diários com disciplinas da base comum, parte diversificada e eletivas. Nessa carga horária, estão previstas cinco horas eletivas por semana, com o objetivo de diversificar o currículo e oportunizar a construção de itinerário formativo de acordo com interesses e projetos de vida no decorrer do ensino médio. Nesse tipo de escola, ocorre um maior tempo de permanência do aluno no ambiente educacional, e esses alunos recebem três refeições diárias.

Já as EEEP foram criadas no Ceará, em 2008, a partir de uma política estadual de educação profissional no escopo do Projeto Brasil Profissionalizado, do Governo Federal, que financiava infraestrutura - ampliação, reforma ou construção de novos prédios - e mobiliário e equipamentos. A adesão do Ceará ao projeto nacional possibilitou a ampliação, num curto espaço de tempo, do número de EEEP, passando de 25, em 2008, para 119 escolas em 2018, contemplando 95 municípios do Ceará, com oferta 52 cursos nas mais diversas áreas de formação profissional (CEARÁ, 2020b).

De acordo com Gonçalves e Santos (2017) a implantação das EEEP no estado do Ceará se propõe a integrar o ensino profissionalizante e o ensino médio regular. Contudo, as autoras destacam que a implementação das EEEP ocorre de forma diferenciada em pelo menos três aspectos: financiamento, processo próprio de seleção de alunos e processo seletivo do quadro docente. Além disso, é importante destacar que as escolas profissionais funcionam em regime de tempo integral, ou seja, em média os alunos entram às $7 \mathrm{~h}$ e saem às $17 \mathrm{~h}$, totalizando 10 horas, e recebem três refeições. 
Santos, Moraes e Albuquerque (2019) afirmam que a orientação dos cursos profissionalizantes é tipicamente vocacional e voltada para o mundo do trabalho, sem que a formação geral deixe de ser contemplada. Nas suas palavras, “esses cursos estão categorizados como educação profissional técnica de nível médio e são ofertados de forma articulada, podendo ainda ser compostos de maneiras distintas" (SANTOS; MORAES; ALBUQUERQUE, 2019, p. 107). Neto et al. (2016) destacam que, nesse tipo de escola, o processo seletivo dos estudantes é realizado por meio da análise do histórico escolar do aluno ao longo do ensino fundamental, caracterizando-se como uma seleção meritocrática em que alunos com notas escolares mais baixas ou com histórico de reprovação tenham poucas chances de conseguir vaga nessas escolas.

Em âmbito nacional, Santos, Moraes e Albuquerque (2019) evidenciam que distintos tipos de ensino médio, ofertados no Brasil, redundam em diferentes resultados obtidos, tanto no que se refere à proficiência, quanto no tocante ao rendimento (aprovação, reprovação ou abandono). A literatura mostra que, embora pertencentes a uma mesma rede estadual de ensino, os diferentes tipos de escola citados produzem resultados de aprendizagem diversos (OLIVEIRA, 2016; NETO et al., 2016; VIEIRA et al., 2016; SANTOS; MORAES; ALBUQUERQUE, 2019). No Ceará tais resultados podem ser verificados a partir do Sistema Permanente de Avaliação da Educação Básica do Ceará (Spaece), uma avaliação de aprendizagem em larga escala, criada em 1992 que é aplicada anualmente nas escolas públicas estaduais e municipais, avaliando o desempenho dos estudantes em Língua Portuguesa e em Matemática nos $2^{\circ}, 5^{\circ}$ e $9^{\circ}$ anos do ensino fundamental e no $3^{\circ}$ ano do Ensino Médio. Pesquisas recentes, como a de Oliveira et al. (2017), evidenciaram uma relação entre o desempenho dos alunos e a tipologia escolar. No entanto, sua amostra só envolveu oito escolas: quatro ER e quatro EEEP.

Considerando o exposto, o objetivo desta pesquisa é investigar a relação entre os diferentes tipos de escolas públicas de ensino médio e o desempenho dos alunos no Spaece, em 2019, em 155 escolas de Fortaleza. Nessa amostra, não estão inseridos os Centros de Educação de Jovens e Adultos (CEJA) nem serão analisados os resultados do Spaece, obtidos pelos alunos matriculados nessa modalidade de educação.

O presente artigo está organizado da seguinte forma: na introdução, foram apresentados a problemática e os objetivos da pesquisa. A primeira seção será dedicada ao Sistema Permanente de Avaliação da Educação Básica do Ceará; na segunda, são apresentados os aspectos metodológicos da pesquisa; na terceira, se dá a discussão dos resultados à luz da literatura da área e, por fim, tecem-se as considerações finais. 


\section{O SISTEMA PERMANENTE DE AVALIAÇÃO DA EDUCAÇÃO BÁSICA DO CEARÁ (SPAECE)}

A década de 1990 é marcada pelo início das políticas neoliberais no Brasil, e é nesse momento em que as avaliações de larga escala começam a ser desenhadas. Ainda no ano de 1990, foi criado e aplicado, pela primeira vez, o Sistema de Avaliação da Educação Básica (Saeb), organizado pelo Instituto Nacional de Estudos e Pesquisas Educacionais Anísio Teixeira (Inep). Nesse período, o Brasil vivia um processo de redemocratização e as reivindicações giraram em torno da universalização da educação básica e da qualidade da educação pública.

A ideia de um sistema de avaliação se desenvolveu ao longo dessa década, sendo amparado por uma legislação nacional que previa sua consolidação e seu financiamento. A LDB de 1996 (Lei no 9.394) vem reafirmar a exigência da universalização desse processo avaliativo educacional e, no seu artigo 87, estabelece que

É instituída a Década da Educação, a iniciar-se um ano a partir da publicação desta Lei. [...] $\int 3^{\circ}$ Cada Município e, supletivamente, o Estado e a União, deverá: [...] IV integrar todos os estabelecimentos de ensino fundamental do seu território ao sistema nacional de avaliação do rendimento escolar (BRASIL, 1996, grifos dos autores).

A avaliação educacional em larga escala no Brasil, seguindo uma tendência mundial, pretende avaliar a qualidade da educação ofertada por meio do desempenho dos alunos e, a partir dos resultados, orientar estratégias e gerar insumos que originem políticas educacionais que elevem a qualidade da educação básica no país.

Nesse sentido, dois anos após o primeiro ciclo do Saeb, o estado do Ceará cria, em 1992, o Sistema Permanente de Avaliação das Escolas Estaduais do Ceará que, anos mais tarde, seria denominado de Sistema Permanente de Avaliação do Ensino no Ceará (Spaece), cuja matriz de referência foi inspirada no Saeb.

Atualmente o Spaece é considerado uma avaliação externa de larga escala, de natureza censitária e que analisa as competências e as habilidades dos alunos do ensino fundamental e do ensino médio em Língua Portuguesa e em Matemática, nas escolas das redes municipais e estadual. De acordo com a Seduc, o Spaece tem por objetivo fornecer subsídios para formulação, reformulação e monitoramento das políticas educacionais, além de possibilitar, aos professores, aos dirigentes escolares e aos gestores, um quadro da situação da educação básica das redes públicas de ensino (CEARÁ, 2020a). 
Ao longo do tempo, o Spaece passou por mudanças conceituais e metodológicas, seguindo de perto a evolução das avaliações de larga escala no país e no mundo. No ano 2000, o sistema de avaliação foi institucionalizado, passando a denominar-se Sistema Permanente de Avaliação da Educação Básica do Ceará (Spaece), constando de duas vertentes: a avaliação do rendimento escolar e a avaliação institucional. A primeira segue uma abordagem mais quantitativa, por ser uma avaliação em grande escala; a segunda, mais qualitativa, por ser, sobretudo, uma avaliação em processo e ter características de autoavaliação das escolas. As duas vertentes não são excludentes. Ao contrário, se complementam, pois uma procura superar as limitações da outra. A partir de 2007, no entanto, a avaliação institucional deixa de ser realizada.

Convém ressaltar que, desde 1994, os levantamentos do Spaece ocorriam em anos alternados, intercalados aos ciclos do Saeb, que eram sempre aplicados nos anos ímpares. A implementação contínua desse sistema de avaliação tem permitido realizar ajustes para melhor atender às demandas do sistema educacional, bem como aperfeiçoar seus procedimentos metodológicos. A partir de 2003, o Spaece passa a ser formalmente utilizado como mecanismo de gestão pública e, em 2007, há um aprofundamento e uma consolidação dessa política, com ampliação do foco e dos desdobramentos da avaliação de larga escala (VIEIRA; VIDAL, 2016). A robustez que o sistema gradativamente alcançou fez com que ele se tornasse um instrumento essencial de gestão da educação pública no estado, uma vez que o conjunto de informações coletadas pelo Spaece sobre o desenvolvimento de habilidades e de competências dos alunos permite diagnosticar a qualidade da educação pública em todo o estado do Ceará (CEARÁ, 2018).

A partir de 2007, o Spaece avalia a alfabetização nas escolas municipais por meio do Spaece-Alfa, aplicada no $2^{\circ}$ ano do ensino fundamental; os $5^{\circ}$ e $9^{\circ}$ anos do ensino fundamental e a $3^{\text {a }}$ série do ensino médio. Em todos os cortes, a periodicidade da aplicação é anual e, por se tratar de um exame de característica longitudinal, possibilita também acompanhar o desenvolvimento dos alunos ao longo do tempo. A partir deste ano, o Spaece passa a ser utilizado como mecanismo que orienta políticas de responsabilização sobre redes municipais e escolas, envolvendo recursos financeiros, prêmios ou bônus. No caso do ensino médio, o Spaece possibilita a construção de rankings de escolas e premia alunos, com microcomputadores, a partir de seus resultados,.

Considerando o Spaece como um sistema de avaliação em larga escala, Santos e Ortigão (2016) destacam que conhecer suas diferentes fases e seus instrumentos é indispensável para professores e gestores, para que entendam melhor os resultados. Todavia, as autoras enfatizam que, devido à complexidade 
da forma como os resultados são analisados para fins de divulgação no ambiente escolar, essa não é uma tarefa fácil, principalmente, no que se refere a conhecer as suas características, suas metodologias e suas implicações curriculares.

De acordo com a Seduc, a escala de proficiência do Spaece é a mesma utilizada pelo Saeb. A variação dessa escala vai de 0 a 500 pontos, sendo que ela está dividida em intervalos de 25 pontos, chamados de níveis de desempenho (CEARÁ, 2018). Embasado nas expectativas de aprendizagem para cada etapa de escolaridade e nas projeções educacionais, estabelecidas pelo Spaece, os níveis da escala são agrupados em intervalos maiores, chamados padrões de desempenho (Figura 1).

\section{Figura 1 - Escalas de proficiência do Ensino Médio na avaliação do Spaece}

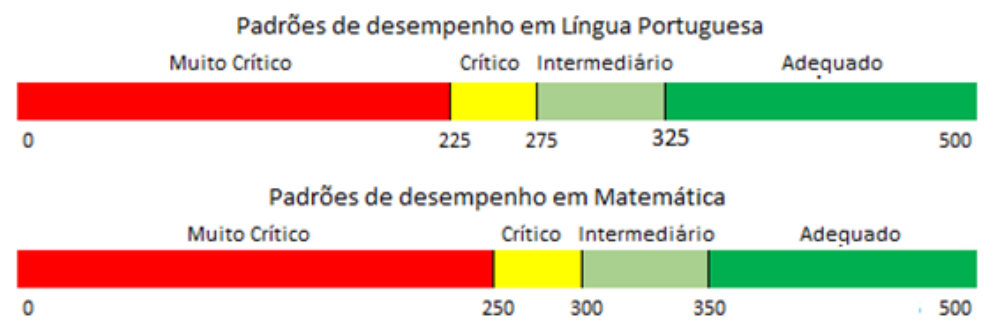

Fonte: Elaboração própria com base nos dados do Spaece (2018)

Cada padrão de desempenho corresponde a um conjunto de tarefas que os alunos são capazes de realizar, de acordo com as habilidades desenvolvidas. Conforme é possível verificar na Figura 1, os resultados intervalares são classificados em quatro padrões de desempenho, denominados muito crítico, crítico, intermediário e adequado (CEARÁ, 2018). Conforme destacam Santos e Ortigão (2016), os valores de proficiência obtidos indicam o grau de desenvolvimento das habilidades que os alunos alcançaram.

Nos últimos dez anos, o Ceará vem se destacando no cenário nacional pelos resultados obtidos nas avaliações de larga escala, com destaque para o Saeb, que compõe o Índice de Desenvolvimento da Educação Básica (Ideb). Embora esses resultados tenham evoluído de forma significativa nos anos iniciais do ensino fundamental, com valores menores nos anos finais desta etapa de ensino, no ensino médio tem se registrado uma incipiente evolução. A expectativa sobre o "efeito onda" - que, ao melhorar os resultados de aprendizagem dos alunos 
nos anos iniciais do ensino fundamental, estes se propagariam para os anos subsequentes do percurso educacional dos estudantes - não se deu na forma esperada.

\section{MATERIAIS E MÉTODOS}

Considerando a questão e o objetivo do artigo, optou-se por uma pesquisa de natureza quantitativa. De acordo com Kauark, Manhães e Medeiros (2010), a pesquisa quantitativa tem como uma de suas características traduzir informações em números, de maneira que elas possam ser classificadas, sistematizadas e analisadas. Quanto aos objetivos, a pesquisa pode ser classificada como descritiva do tipo documental, porque pretende analisar materiais que não receberam tratamento analítico (KAUARK; MANHÃES; MEDEIROS, 2010).

Nesse sentido, inicialmente foi realizada uma pesquisa a partir de informações sobre o resultado do ensino médio no Spaece no ano de 2019, disponibilizados no site da Secretaria da Educação do Ceará (Seduc). Posteriormente, procurou-se relacionar o desempenho dos alunos com informações do Censo Escolar, disponível no site do Instituto Nacional de Estudos e Pesquisas Educacionais Anísio Teixeira (Inep).

$\mathrm{Na}$ análise do desempenho foi considerado o somatório das proficiências de Língua portuguesa e de Matemática (Equação1).

\section{Equação 1}

$$
\mathrm{D}=\mathrm{LP}+\mathrm{MT}
$$

Desempenho $=\mathrm{D}$

Proficiências em língua portuguesa $=$ LP

Proficiências em matemática $=$ MT

Considerando o escopo da pesquisa foram analisados os desempenhos de 155 escolas estaduais da cidade de Fortaleza, Ceará, com auxílio da planilha Excel 2016 e do Software JASP statistic, versão 0.12.0.0.

No Quadro 1, são apresentadas as variáveis analisadas, que, posteriormente, serão relacionadas com o desempenho dos alunos. 


\section{Quadro 1 - Lista de variáveis analisadas}

\begin{tabular}{|c|c|}
\hline Variável & Descrição \\
\hline Desempenho & Somatório das proficiências em Língua portuguesa e em Matemática \\
\hline CAE & Categoria escolar \\
\hline ATU & Média de alunos por turma (ATU) \\
\hline AHA & Média de horas aulas diárias (AHA) \\
\hline DSU & Docentes com nível superior (DSU) \\
\hline IRD & Indicador de regularidade do corpo docente (IRD) \\
\hline ICG & Indicador de complexidade de gestão da escola (ICG) \\
\hline
\end{tabular}

Fonte: Elaboração própria

Por fim, pretende-se relacionar o desempenho escolar com as variáveis citadas, comparando as categorias escolares, o que será feito na próxima seção, por meio dos resultados encontrados.

\section{RESULTADOS E DISCUSSÕES}

Conforme descrito, o objetivo do artigo é fazer uma análise dos resultados de desempenho dos alunos da $3^{\text {a }}$ série do ensino médio no Spaece 2019, considerando as categorias de escolas existentes na rede pública de ensino médio do Ceará. Para melhor compreensão dos resultados obtidos, será apresentado primeiramente um panorama dos resultados gerais.

Nesse sentido, foram analisadas as notas de desempenho de 155 escolas estaduais da cidade de Fortaleza. A nota do desempenho médio de cada escola foi composta pelo somatório das proficiências em Língua Portuguesa e em Matemática. Uma síntese dos resultados é mostrada na Tabela 1.

\section{Tabela 1 - Descrição dos resultados das escolas no Spaece 2019}

\begin{tabular}{cc}
\hline \multicolumn{3}{c}{ Desempenho } \\
\hline $\mathrm{N}$ & 155 \\
Média & 542,89 \\
Mediana & 532,13 \\
Moda & 481,31 \\
Desvio Padrão & 40,47 \\
Variância & $1.637,42$ \\
Mínimo & 481,31 \\
Máximo & 670,51 \\
\hline
\end{tabular}

Fonte: Elaboração própria 
$\mathrm{Na}$ Tabela 1, são apresentados os resultados brutos sem a exclusão de discrepantes (outliers). De acordo com Oliveira (2016), os outliers são valores atípicos que diferem substancialmente da maioria do conjunto de dados; e, para Larson e Farber (2017), os outliers são valores incomuns/discrepantes que influenciaram a média do clusters. Considerando que a média é a medida mais usual e confiável, pois leva em conta cada elemento de um conjunto de dados, entendese que os valores discrepantes (outliers) poderão influenciar tendenciosamente a compreensão do conjunto (OLIVEIRA, 2016).

Por conseguinte, de acordo com a Tabela 1, é possível observar um elevado desvio padrão $(\sigma=40,47)$ e, consequentemente, uma elevada variância $\left(\sigma^{2}\right.$ $=1.637,42)$. Esses resultados evidenciam alta discrepância no desempenho das escolas, que pode ser justificada pela presença de outliers (Gráfico 2) e ratificada ao observar a distribuição do Gráfico 1.

\section{Gráfico 1 - Distribuição das notas de desempenho médio}

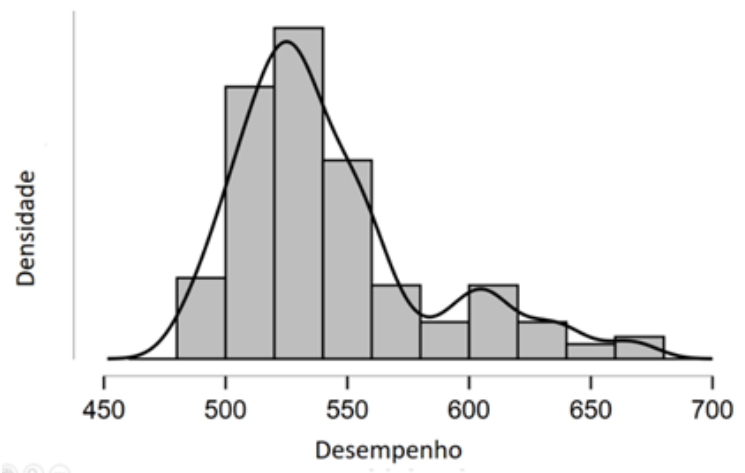

Fonte: Elaboração própria

Conforme é possível observar no Gráfico 1, a curva tende a uma normalidade na distribuição, todavia há uma assimetria no lado direito, o que significa que algumas escolas tiveram resultados muito divergentes (outliers) e com valores extremos, principalmente, os resultados acima de 600 pontos. Nesse sentido, por meio do boxplot (Gráfico 2), é possível visualizar quais e quantas foram as escolas com valores discrepantes, ou seja, com outliers, do conjunto de dados. 


\section{Gráfico 2 - Distribuição das notas de desempenho médio para identificar outliers}

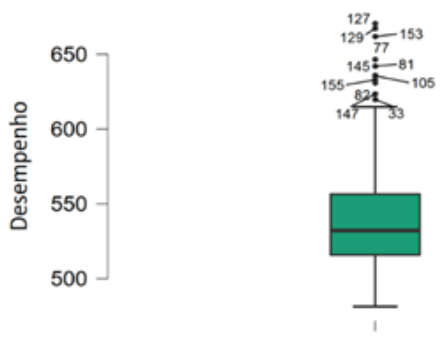

Escolas

Fonte: Elaboração própria

Ao considerar o conjunto das escolas públicas de Fortaleza, percebe-se uma discrepância elevada de algumas escolas da rede estadual de ensino médio que destoam da maioria, cuja média é 542,89 pontos. Esse valor é bem aproximado da mediana, de 532,13 pontos.

Considerando a diversificação da oferta de ensino médio, resolveu-se classificar e analisar as notas por categoria de escola, que, para este estudo, foram organizadas em três clusters: tipo 1 - Escola de Ensino Médio Regular (ER); tipo 2 - Escolas de Ensino Médio em Tempo Integral (EEMTI); tipo 3 - Escola Estadual de Educação Profissional (EEEP). Vale destacar que, nesta pesquisa, foram excluídos outros tipos de oferta de ensino médio, como a que é feita nos Centros de Educação de Jovens e Adultos (CEJA), por ser uma modalidade de ensino que possui características diferenciadas (CEARÁ, 2020a).

Das 155 escolas, foram analisadas as notas de um total de 22.202 alunos, sendo 14.404 alunos de 86 escolas regulares, 4.986 estudantes de 48 escolas de tempo integral e de 2.812 alunos de 21 escolas de educação profissional. Foi verificado se há diferenças no desempenho dos alunos dessas escolas, considerando o tipo de oferta, como é possível observar nos Gráficos 3a e 3b. 


\section{Gráfico 3 - Comparação dos desempenhos entre os diferentes tipos de escolas}
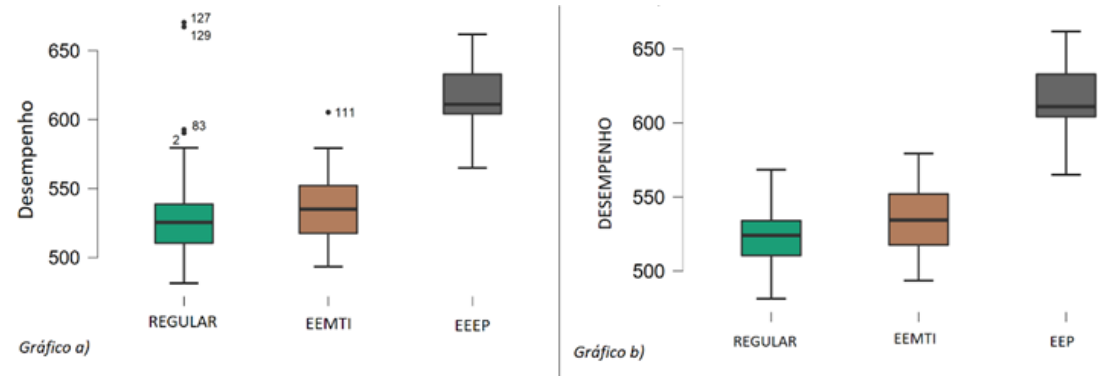

Fonte: Elaboração própria

O Gráfico 3a mostra os resultados encontrados sem a exclusão dos outliers. Considerando que a média leva em consideração todos os valores, sendo, portanto, influenciada pelos outliers (LARSON; FARBER, 2017), os valores dos desempenhos das escolas $(2,83,127,129)$ foram substituídos pela média do cluster ER, e o desempenho da escola 111 foi substituído pela média do cluster EEMTI. Sendo assim, após a substituição, os valores se encontram representados no Gráfico 3b.

Conforme é possível visualizar no Gráfico 3a, foi identificado um número maior de outliers nas escolas regulares, o que aponta para uma maior heterogeneidade neste cluster do que nas EEMTI e nas EEEP. Além disso, os resultados mostraram uma semelhança entre a média das ER $(523,42)$ e das EEMTI $(534,11)$.

Estes resultados confirmam o que Santos e Ortigão (2016, p. 60) chamam a atenção, ao afirmarem que "as avaliações e seus resultados tiveram o mérito de revelar os processos de desigualdades que permeiam os sistemas educativos". Contudo vale destacar que, além das diferenças já existentes e apontadas na literatura entre as escolas públicas e particulares (FERREIRA; TABAQUIM, 2017), existem diferenças expressivas também entres os tipos de escolas públicas. Esses resultados também vão ao encontro da pesquisa de Neto et al. (2016) ao evidenciarem que as escolas regulares são as que apresentam piores resultados nas avaliações externas.

Nesse sentido, cabe destacar que os resultados mostram também que as EEEP, com média de 616,45, além de serem mais homogêneas, tiveram um desempenho superior as ER e as EEMTI (Tabela 2). 


\section{Tabela 2 - Descrição do desempenho por categoria escolar}

\begin{tabular}{cccc}
\hline & \multicolumn{3}{c}{ Desempenho } \\
\cline { 2 - 4 } & Regular & EEMTI & EEEP \\
\hline $\mathrm{N}$ & 86 & 48 & 21 \\
Média & 523,42 & 534,11 & 616,45 \\
Mediana & 524,06 & 534,43 & 611,05 \\
Moda & 524,06 & 493,49 & 565,02 \\
Desvio Padrão & 19,24 & 21,33 & 21,75 \\
Variância & 370,15 & 454,93 & 472,87 \\
Mínimo & 481,31 & 493,49 & 565,02 \\
Máximo & 568,41 & 579,37 & 661,83 \\
\hline
\end{tabular}

Fonte: Elaboração própria

$\mathrm{Na}$ tentativa de investigar os possíveis fatores que poderiam influenciar essa diferença de resultados por clusters, resolveu-se pesquisar a influência de pelo menos cinco variáveis: média de alunos por turma (ATU); média de horas aulas diárias (AHA); docentes com nível superior (DSU); indicador de regularidade do corpo docente (IRD); nível de complexidade de gestão da escola (ICG). A fonte de consulta de tais informações foi o Censo da Educação Básica 2019, disponibilizado no site do Inep, numa aba denominada Indicadores Educacionais.

Média de alunos por turma (ATU)

Com relação à variável média de alunos por turma (ATU), os resultados mostraram que não há diferenças significativas entre as ER, EEMTI e EEEP (Gráfico 4). Não obstante, percebe-se que a média de alunos por turma é superior nas EEEP.

\section{Gráfico 4 - Descrição do desempenho por categoria escolar}

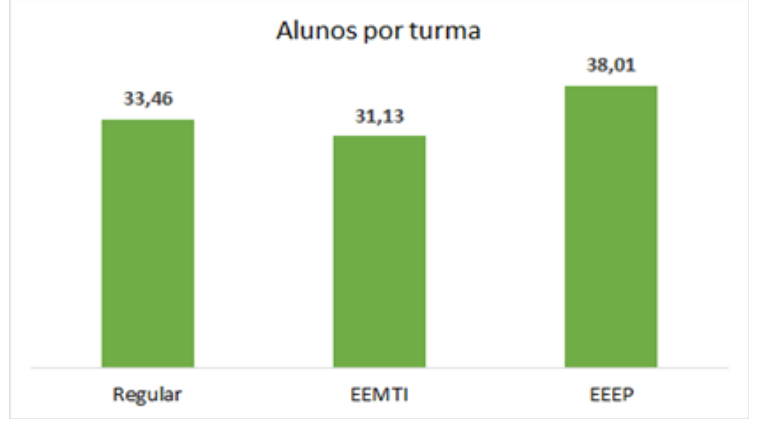

Fonte: Elaboração própria 
Contudo, não foi possível identificar o tamanho das salas de aula e a relação aluno por metro quadrado, haja vista que essas são informações importantes que influenciam as condições técnicas de aprendizagem. Segundo publicação Docentes en Iberoamérica: Análisis de PISA y TALIS (2018), da OCDE, turmas com um menor número de alunos beneficiam a aprendizagem, especialmente daqueles que estão dos anos iniciais da educação básica.

Além disso, percebe-se que o valor absoluto de matrículas ${ }^{1}$ das escolas regulares (17.172 alunos) é superior ao valor absoluto de matrículas das EEMTI (6.903 alunos) e das EEEP (2.818 alunos), e esse fator não pode ser ignorado. De acordo com Neto et al. (2016), a existência de um número alto de alunos matriculados em escolas regulares, de menor prestígio, coloca a hierarquização e a busca pela redução da iniquidade em um patamar diferente.

\section{Horas-aula diárias}

Quanto ao número médio de horas-aula diárias por escola do Ensino Médio, os resultados mostraram que as EEEP têm médias de 9,56 horas-aula, similares às EEMTI, que possuem 8,07 horas-aulas, enquanto as ER apresentem média diária de 4,61 horas. Essa diferença chega a ser praticamente o dobro de horas-aula (Tabela 3).

\section{Tabela 3 - Descrição do desempenho por categoria escolar}

\begin{tabular}{cccc}
\hline & \multicolumn{3}{c}{ Média de horas aulas diárias } \\
\cline { 2 - 4 } & Regular & EEMTI & EEEP \\
\hline $\mathrm{N}$ & 86 & 48 & 21 \\
Média & 4,61 & 8,07 & 9,56 \\
Mediana & 4,50 & 9,30 & 9,50 \\
Moda & 4,50 & 9,70 & 9,50 \\
Desvio Padrão & 0,68 & 1,97 & 0,28 \\
Variância & 0,46 & 3,88 & 0,08 \\
Mínimo & 3,60 & 4,10 & 8,70 \\
Máximo & 9,40 & 10,50 & 10,00 \\
\hline
\end{tabular}

Fonte: Elaboração própria

Conforme é possível perceber na Tabela 3, existe uma diferença expressiva entre as cargas horárias quando se compara as ER com as EEEP e as EEMTI. Contudo, vale destacar que, apesar da diferença expressiva da carga horária entre as ER e EEMTI, o desempenho no Spaece nos dois clusters são 
semelhantes (Tabela 2). Já em relação à similaridade de carga horária das EEMTI e EEEP, acredita-se que a diferença de resultados de desempenho entre as escolas pode ter influência de fatores associados ao processo seletivo dos alunos e às condições de infraestrutura das escolas.

De acordo com Vieira et al. (2016, p. 72), além do processo seletivo adotado pelas EEEP para o ingresso de estudantes, a diferença no regime da carga horária por dia entres esses três tipos de escola "impõe critérios que levam à exclusão de parcela expressiva de jovens, aumentando a iniquidade entre escolas, alunos e até mesmo condições laborais dos professores e gestores". De fato, enquanto as ER funcionam nos turnos diurnos e noturno, as EEMTI e EEEP possuem oferta exclusivamente diurna.

Percentual de funçôes docentes com curso superior (DSU)

Quanto ao percentual de docentes com curso superior, os resultados mostram que há similaridades entre as ER e as EEMTI. Contudo, vale destacar que o desvio padrão é maior entres as escolas regulares $(\sigma=4,37 \%)$ e as EEMTI $(\sigma=5,01 \%)$, o que significa que, nessas escolas, há uma maior discrepância do percentual do quadro docente com curso superior, já que esse é o percentual médio (Tabela 4).

Tabela 4 - Descrição do desempenho por categoria escolar

\begin{tabular}{cccc}
\hline & \multicolumn{3}{c}{ \% de funções docentes com curso superior } \\
\cline { 2 - 4 } & Regular & EEMTI & EEEP \\
\hline N & 86 & 48 & 21 \\
Média & $96,33 \%$ & $95,53 \%$ & $98,82 \%$ \\
Mediana & $97,50 \%$ & $96,35 \%$ & $100,00 \%$ \\
Moda & $100,00 \%$ & $100,00 \%$ & $100,00 \%$ \\
Desvio Padrão & $4,37 \%$ & $5,01 \%$ & $1,77 \%$ \\
Variância & $19,11 \%$ & $25,12 \%$ & $3,12 \%$ \\
Mínimo & $81,50 \%$ & $78,60 \%$ & $94,70 \%$ \\
Máximo & $100,00 \%$ & $100,00 \%$ & $100,00 \%$ \\
\hline
\end{tabular}

Fonte: Elaboração própria

Por outro lado, percebe-se que as EEEP, além de terem um percentual maior de docentes com curso superior $(98,82 \%)$, têm variância $\left(\sigma^{2}=3,12 \%\right)$ e desvio padrão menor ( $\sigma=1,77 \%)$, o que significa que essa categoria é mais homogênea quando se refere ao percentual de docentes com curso superior. 
O Indicador de Regularidade do Corpo Docente (IRD) tem por objetivo avaliar a regularidade do corpo docente nas escolas de educação básica a partir da observação da permanência dos professores nas escolas nos últimos cinco anos (2015 a 2019). Esse indicador pode variar de 0 a 5, de forma que, quanto mais próximo de 0 , mais irregular é o vínculo do docente com a escola e quanto mais próximo de 5, mais regular (BRASIL, 2019).

Os resultados mostraram que, com relação a essa variável, as três categorias escolares tiveram valores do indicador semelhantes: $\mathrm{ER}$ (IRD $=3,17$; $\sigma=0,394)$ EEMTI (IRD $=3,11 ; \sigma=0,425)$, EEEP (IRD $=3,20 ; \sigma=0,431$ ). Sendo assim, considerando que o IRD representa a regularidade média do corpo docente da escola, pode-se inferir que essa variável não apresentou evidências de ter influenciado significativamente no desempenho das escolas no Spaece.

Indicador de complexidade de gestão da escola (ICG)

De acordo com Gonçalves e Santos (2017), uma das variáveis significativas dos diferentes tipos de escolas é a gestão escolar. Nesse sentido, foi investigada, também, a relação entre desempenho e a complexidade de gestão da escola (ICG) das escolas públicas de nível médio de Fortaleza. O ICG está relacionado a algumas características que poderão afetar o desempenho acadêmico que são porte da escola, número de turnos de funcionamento, quantidade e complexidade de modalidades/etapas de ensino oferecidas (INEP, 2014).

Consideradas essas características, as escolas são classificadas em níveis de 1 a 6 de acordo com sua complexidade de gestão, os níveis elevados indicam maior complexidade. No Quadro 2 são descritos os níveis de complexidade de acordo com as características predominantes das escolas pertencentes a cada um deles. 


\section{Quadro 2 - Descrição dos níveis de complexidade de gestão}

\begin{tabular}{|c|l|}
\hline Nivel 1 & $\begin{array}{l}\text { Escolas que, em geral, possuem porte inferior a } 50 \text { matrículas, funcionam em único turno, ofertam uma única } \\
\text { etapa de ensino e apresentam a Educação Infantil ou os Anos Iniciais como etapa mais elevada }\end{array}$ \\
\hline Nivel 2 & $\begin{array}{l}\text { Escolas que, em geral, possuem porte entre } 50 \text { e } 300 \text { matrículas, funcionam em } 2 \text { turnos, com oferta de até } 2 \\
\text { etapas de ensino e apresentam a Educação Infantil ou os Anos Iniciais como etapa mais elevada }\end{array}$ \\
\hline Nivel 3 & $\begin{array}{l}\text { Escolas que, em geral, possuem porte entre } 50 \text { e } 500 \text { matrículas, funcionam em } 2 \text { turnos, com oferta de } 2 \text { ou } 3 \\
\text { etapas de ensino e apresentam os Anos Finais como etapa mais elevada }\end{array}$ \\
\hline Nível 4 & $\begin{array}{l}\text { Escolas que, em geral, possuem porte entre } 150 \text { e } 1000 \text { matrículas, funcionam em } 2 \text { ou } 3 \text { turnos, com oferta } \\
\text { de } 2 \text { ou } 3 \text { etapas de ensino e apresentam o Ensino Médio, a Educação Profissional ou a EJA como etapa mais } \\
\text { elevada }\end{array}$ \\
\hline Nivel 5 & $\begin{array}{l}\text { Escolas que, em geral, possuem porte entre } 150 \text { e } 1000 \text { matrículas, funcionam em } 3 \text { turnos, com oferta de } 2 \text { ou } 3 \\
\text { etapas de ensino e apresentam a EJA como etapa mais elevada }\end{array}$ \\
\hline Nível 6 & $\begin{array}{l}\text { Escolas que, em geral, possuem porte superior a } 500 \text { matrículas, funcionam em } 3 \text { turnos, com oferta de } 4 \text { ou } \\
\text { mais etapas de ensino e apresentam a EJA como etapa mais elevada }\end{array}$ \\
\hline
\end{tabular}

Fonte: Elaboração própria adaptado dos dados da nota técnica do Inep (2014)

Os resultados mostram a existência de uma relação entre desempenho e a complexidade de gestão da escola (ICG). Conforme é possível observar nos Gráficos 5a e 5b, as escolas com maiores níveis de complexidade de gestão tiveram pior desempenho na avaliação do Spaece.

\section{Gráfico 5 - Descrição da relação entre desempenho escolar e a complexidade de gestão da escola (ICG)}

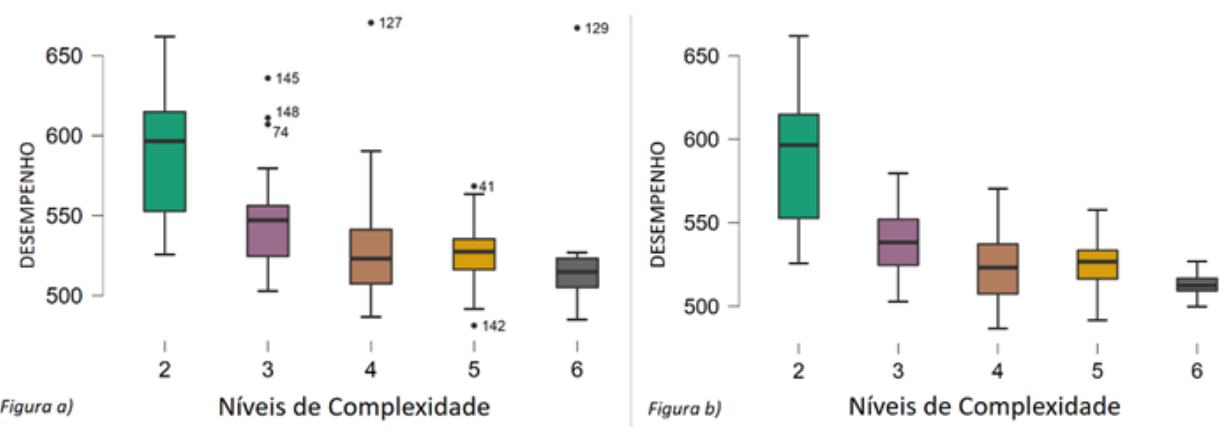

Fonte: Elaboração própria

Conforme é possível observar, no Gráfico 5a, alguns outliers foram identificados nos clusters de níveis 3, 4, 5, e 6 e os valores de seus desempenhos substituídos pela média de seus respectivos clusters. Ao analisar o ICG por tipo escolar essa relação se intensifica, conforme é possível verificar no Gráfico 6. 


\section{Gráfico 6 - Descrição da relação entre desempenho escolar e a complexidade de gestão da escola (ICG)}

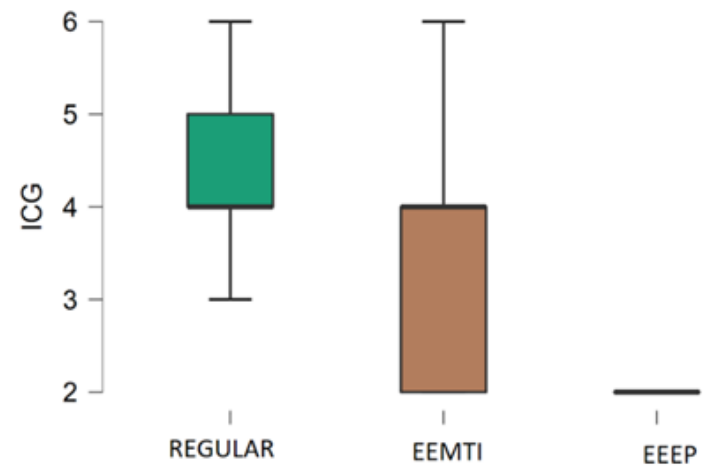

Fonte: Elaboração própria

Conforme é possível verificar, os resultados mostram que, quanto maior a complexidade da gestão, menor é o desempenho da escola no Spaece. Esses resultados coadunam com os de Gonçalves e Santos (2017, p. 177), ao afirmarem que, além das EEEP “terem melhores disposições econômicas, sociais e culturais, ainda estão inseridas num tipo de escola privilegiada em termos de orçamento, gestão e prática pedagógica".

Nesse sentido, cabe destacar que, apesar de nem todas as variáveis estudadas terem apresentado diferenças significativas com relação aos clusters organizados, de modo geral, percebe-se que os resultados entre os diferentes tipos de escolas públicas de ensino médio no Ceará, em Fortaleza, revelam um problema antigo da educação brasileira já preconizado por Gonçalves e Santos (2017) e por Vieira et al. (2016), que são as desigualdades sociais em termos de acesso a oportunidades educacionais (MARTELETO, 2002).

Nesse sentido, Vieira et al. (2016, p.72) destacam que

As transformações no perfil demográfico dos alunos, das famílias, dos docentes, aliadas às condições de infraestrutura das escolas de atendimento integral, acentuam as desigualdades das oportunidades educacionais. Embora se pretenda ampliar a abrangência e cobertura da demanda, a política diferenciada das escolas, de certo modo, também acaba por se tornar mais seletiva, acentuando as desigualdades. A "escolha" do tipo de ensino médio acaba sendo orientada pelo perfil do aluno, sua situação socioeconômica, seu rendimento escolar ou mesmo seu comportamento. 
Nesse sentido, é possível perceber que os critérios de seleção de alunos acentuam ainda mais as desigualdades nas oportunidades de acesso educacional nos diferentes tipos de escolas públicas cearenses. Ademais, vale destacar que a influência do nível socioeconômico dos estudantes no desempenho escolar já foi evidenciada em outros países e, portanto, também já vem sendo bastante debatida desde o Relatório Coleman (1968).

De modo geral, após analisar os resultados da pesquisa constata-se que, apesar da nomenclatura diferente, os três tipos de oferta escolar de ensino médio no Ceará apresentam analogia com os tipos propostos por Cerqueira e Sawyer (2007): uma escola com condições precárias de infraestrutura e indicadores deficientes de desempenho acadêmico, que seriam as ER; outro, com escolas com boas condições de infraestrutura e bons indicadores de desempenho, que seriam as EEEP; e um terceiro perfil, que ficou em uma posição intermediária, que seriam as EEMTI.

Nesse sentido, Santos e Ortigão (2016) enfatizam que os dados dessa avaliação de larga escala estadual servem apenas para evidenciar alguns problemas a serem superados, dentre eles, a igualdade de acesso ao ensino básico, a sua universalização e a qualidade do rendimento escolar. Ademais, Oliveira et al. (2017) destacam que o sucesso do desempenho acadêmico da escola é fortemente influenciado por diversos fatores intra e extraescolares, como oportunidades oferecidas pela família e pela sociedade e o clima escolar. Para os autores, o clima escolar diz respeito a um "conjunto de características sociais, culturais e psicológicas da escola, que se relacionam de forma interativa e influenciam a aprendizagem e o desempenho dos estudantes" (OLIVEIRA et al., 2017, p. 984).

Destarte, considerar apenas o resultado final de uma avaliação de larga escala como o Spaece, sem considerar que os alunos tiveram diferentes condições de aprendizagem (carga horária, infraestrutura escolar, número de alunos por turma, nível de formação dos professores) induz a uma evidência tendenciosa e a uma compreensão estreita e reduzida do sentido de "qualidade" do ensino público (SANTOS; ORTIGÃO, 2016), e, portanto, não revela o real efeito das políticas educacionais para o ensino médio cearense.

Por fim, acredita-se que os efeitos decorrentes das desigualdades de desempenho dos alunos nos três tipos de escolas poderiam ser minimizados se fossem dadas as mesmas condições de acesso, sem processo seletivo e, com a livre escolha dos alunos às escolas de educação profissional e de tempo integral. A diversificação da oferta de ensino médio e o acesso a alguns tipos de escola por meio de seleção com uso de histórico escolar (critério de nota) configurase como mais uma forma de promover desigualdade para os alunos da escola pública. Além da nota como um critério limitante, tem-se a localização geográfica, 
obstáculos socioeconômicos e outras dificuldades que condicionam o livre acesso a essas instituições. Dessa maneira, uma parcela de alunos desejosos em estudar numa escola com maiores possibilidades de aprendizagem e desenvolvimento não alcançam esse objetivo.

\section{CONSIDERAÇÕES FINAIS}

O objetivo desta pesquisa foi investigar a relação entre os diferentes tipos de escolas públicas de Ensino Médio na cidade de Fortaleza e o desempenho de seus alunos no Sistema Permanente de Avaliação da Educação Básica do Ceará (Spaece). Para isso foram analisados os indicadores de média de alunos por turma (ATU), horas-aulas diária (AHA), indicador de regularidade do corpo docente (IRD), percentual de funções docentes com curso superior (DSU) e o indicador de complexidade de gestão da escola (ICG). A primeira constatação diz respeito às diferenças entre os tipos de escolas da rede pública - ER, EEMTI e EEEP sendo que a Escola Regular apresenta a maior heterogeneidade de indicadores e os piores resultados no Spaece.

Os resultados mostram que, das variáveis analisadas, o indicador de complexidade de gestão da escola foi o que apresentou maior diferença entre as ER quando comparadas com as EEEP, todavia, as horas-aulas diárias não foram tão relevantes quando feita a comparação entre as EEMTI e as EEEP, já que estas têm carga horária de aulas semelhantes. Este fato, não isoladamente, ajudou a desvendar possíveis razões para o desempenho inferior das escolas regulares.

Nos demais indicadores, embora os valores não tenham explicitado alguma discrepância, conseguiu-se identificar nuances associadas às variáveis que podem tornar mais compreensível a análise dos resultados, como é o caso da quantidade de aluno por turma. Nessa variável, os resultados foram muito similares, no entanto, o valor absoluto das matrículas na escola regular é mais de 2 vezes superior ao dos outros dois tipos de escolas. Esse é um fator que demonstra a seletividade que existe no interior da rede estadual e que isso deve ter impacto na aprendizagem e desempenho dos alunos.

Outros indicadores relacionados aos docentes mostram que o percentual de docentes com o curso superior e regularidade do corpo docente foi equiparado entre os tipos de escola, levando a inferir que esse fator não influencia significativamente o desempenho das escolas no exame ou, por serem muito semelhantes, não é possível mensurar o impacto dessas variáveis. Essa percepção reflete o pensamento de Fernandes e Gremaud (2009, p. 216) quando afirmam que "é preciso reconhecer que todas as medidas utilizadas em avaliações educacionais são imperfeitas, por não levarem em conta todos os aspectos que se 
gostaria de considerar e por medir". Os resultados da pesquisa evidenciam que existem muitos fatores fora dos indicadores que são importantes de se considerar ao analisar diferentes resultados de desempenho entre os tipos de escola.

O que se percebe com estudos dessa natureza é que o acervo de dados sobre avaliação de larga escala associado à coleta anual do Censo escolar pode permitir um amplo conjunto de análises sobre relação e correlação entre variáveis extra e intraescolares que ajude a compreender o trabalho das escolas, dos professores e o esforço de aprendizagem dos alunos.

\section{REFERENNCIAS}

BRASIL. Lei n 9.394, de 20 de dezembro de 1996. Estabelece as diretrizes e bases da educação nacional. Diário Oficial da União, Brasília, DF, 23 dez. 1996. Seção 1, p. 27833. Disponível em: http://www.planalto.gov.br/ccivil_03/leis/ 19394.htm. Acesso em: 20 abr. 2020.

BRASIL. Indicadores educacionais: educação básica. Brasilia: INEP, 2019. Disponível em: http://inep.gov.br/web/guest/indicadores-educacionais. Acesso em: 20 abr. 2020.

CASAGRANDE, Ana Lara; ALONSO, Katia Morosov. Sistema econômico, direitos sociais e escolas desiguais: reflexões sobre a reforma do ensino médio. Revista Brasileira de Política e Administração da Educação, v. 35, n. 3, 2019. Disponível em: https://seer.ufrgs.br/rbpae/ article/view/93846. Acesso em: 20 abr. 2020.

CEARÁ. Sistema Permanente de Avaliação da Educação Básica do Ceará: boletim do sistema. v. 3, Juiz de Fora, 2018. Disponível em: http://www.spaece. caedufjf.net/ colecao/2018-2/. Acesso em: 15 de mar. 2020.

CEARÁ. Spaece. Disponível em: https://www.seduc.ce.gov.br/2018/01/01/ spaece/. Acesso em: 15 de mar. 2020a.

CEARÁ. Educação profissional. Disponível em: https://educacaoprofissional. se duc.ce.gov.br/index.php?option=com_content\&view $=$ featured\&Itemid=101. Acesso em: 15 de mar. 2020b. 
CERQUEIRA, Cezar Augusto; SAWYER, Diana Reiko Oya Tutya. Tipologia dos estabelecimentos escolares brasileiros. Revista Brasileira de Estudos de População, v. 24, n. 1, p. 53-67, 2007. Disponível em: https://www.scielo.br/ scielo.php?script $=$ sci_arttext\& pid=S0102-30982007000100005\&lng=pt\&nrm $=$ iso\&tlng=pt. Acesso em: 15 de mar. 2020.

COLEMAN, James S. The concept of equality of educational opportunity. Harvard Educational Review, v. 38, n. 1, p. 7-22, 1968. Disponível em: https:// hepgjournals.org/ doi/10.17763/haer.38.1.m3770776577415m2.

FERNANDES, Reynaldo.; GREMAUD, Amaury. Qualidade da educação: avaliação, indicadores e metas. In: Veloso, F. et al. (Org.). Educação básica no Brasil: construindo o país do futuro. Rio de Janeiro: Elsevier, 2009. p. 213-238. Disponível em: https://www.cps.fgv.br/ibrecps/rede/seminario/reynaldo_ paper.pdf. Acesso em 16 abr. 2020.

GONÇALVES, Danyelle Nilin; SANTOS, Harlon Romariz Rabelo. Quem são os alunos das escolas estaduais de educação profissional do Ceará? Um estudo sobre o perfil socioeconômico. O Público e o Privado, n 29, jan/jun, 2017. Disponível em: http://www.seer.uece.br/?journal=opublicoeoprivado\&page=ar ticle\&op $=$ view\&path $\% 5 B \% 5 \mathrm{D}=1506$. Acesso em: 16 abr. 2020.

INEP. Indicador para mensurar a complexidade da gestão nas escolas a partir dos dados do Censo Escolar da Educação Básica. Nota técnica 040/2014. Brasília, DF, 2014. Disponível em: http://download.inep.gov.br/informacoes_ estatisticas/indicadores_educa cionais/ 2014/escola_complexidade_gestao/ nota_tecnica_indicador_escola_complexi dade_gestao.pdf. Acesso em 16 abril 2020.

KAUARK, Fabiana Silva; MANHÃES, Fernanda Castro; MEDEIROS, Carlos Henrique. Metodologia da pesquisa: guia prático. Itabuna:Via Litterarum, 2010.

LARSON, Ron; FARBER, Betsy. Elementary Statistics: Picturing the World. 7th edition. Boston, MA: Pearson education, 2017. 
MARTELETO, Letícia. Desigualdade regional e intergeracional de oportunidades: a matrícula e a escolaridade de crianças e jovens no Brasil. In: ENCONTRO NACIONAL DE ESTUDOS DE POPULAÇÃO, 13, 2002, Ouro Preto, Anais... Belo Horizonte, 2002. Disponível em: file:///C:/Users/Jo\%C3\%A3oBatista/ Downloads/1243-3614-1-PB.pdf. Acesso em: 16 abr. 2020.

NETO, Ruy Mello. et al. Ensino médio: uma escola de qualidade para todos e para cada um? Cadernos Cenpec Nova série, [S. 1.], v. 6, n. 2, jun. 2016. Disponível em: http://cadernos.cenpec.org.br/cadernos/index.php/cadernos/article/ view/367. Acesso em: 16 abr. 2020.

OCDE. Docentes en Iberoamérica: Análisis de PISA y TALIS. 2018. Disponível em: http://www.oecd.org/skills/piaac/Docentes $\% 20$ en $\% 20$ iberoame \%CC\%81 rica\%20PISA.pdf. Acesso em 9 dez. 2019.

OLIVEIRA, José Valmir Guimarães. Análise do Sistema Permanente de Avaliação da Educação Básica do Ceará (Spaece): um estudo comparativo entre o efeito escola e os resultados de proficiência em escolas da rede estadual nos anos de 2012 a 2014. Dissertação (Mestrado em Educação). Programa de Pós-Graduação em Educação, Universidade Federal do Ceará, Fortaleza, 2016. Disponível em: http://repositorio.ufc.br/handle/riufc/22143. Acesso em: 16 abr. 2020.

OLIVEIRA, José Valmir Guimarães; GUIMARÃES, Ariadina Torres; FILHO, Nicolino Trompieri; MAIA, Alberto Filho Maciel. Análise comparativa entre o efeito escola e os resultados de proficiência em escolas da rede estadual nos anos de 2012 a 2014, usando os dados dos Spaece - Sistema Permanente de Avaliação da Educação Básica do Ceará. In: VII International Congress in Education Assessment, 7, 2017, Fortaleza/CE. Anais...Fortaleza: UFC, 2017, p. 981-1000. Disponível em: http://www.nave.ufc.br/vii_ciae/. Acesso em: 16 abr. 2020.

SANTOS, Maria José Costa; ORTIGÃO, Maria Isabel Ramalho. Tecendo redes intelectivas na Matemática nos anos iniciais do ensino fundamental: relações entre currículo e avaliação externa (Spaece). REMATEC, V. 11, n. 22, 2016. Disponível em: http://rematec.net.br/ index.php/rematec/article/view/70. Acesso em: 16 abr. 2020. 
SANTOS, Robson; MORAES, Gustavo Henrique; ALBUQUERQUE, Ana Elizabeth M. Diferenças de rendimento e fluxo entre os tipos de oferta do ensino médio: uma análise exploratória. Cadernos de Estudos e Pesquisas em Políticas Educacionais, v. 3, p. 24-24, 2019. Disponível em: http://rbep.inep. gov.br/ojs3/index.php/cadernos/article/view/3993. Acesso em: 16 abr. 2020.

FERREIRA, Fabiana Ribas; TABAQUIM, Maria de Lourdes Merighi. Habilidades cognitivas de escolares do ensino público e privado: estudo comparativo de précompetências para a aprendizagem acadêmica. Revista Psicopedagogia, v. 34, n. 104, p. 126-136, 2017. Disponível em http://pepsic.bvsalud.org/scielo. php? script $=$ sci_arttext\&pid $=$ S0103-84862017000200003\&lng $=$ pt\&nrm $=$ iso. Acessos em: 18 abr. 2020.

VIEIRA, Sofia Lerche; VIDAL, Eloísa Maia; FREITAS, Pâmela Felix; BATISTA, Antônio Augusto Gomes. Reações das políticas educacionais estaduais nas escolas: um estudo de caso em escolas do Ceará, Goiás, Pernambuco e São Paulo. Cadernos Cenpec, v. 6, n. 2, 2016. Disponível em: http://cadernos.cenpec.org. br/cadernos/index.php/cadernos/article/view/ 360. Acesso em: 16 abr. 2020.

VIEIRA, Sofia Lerche; VIDAL, Eloísa Maia. Ensino médio no Ceará: igualdade versus qualidade na implementação do direito à educação. Cadernos Cenpec, v. 6, n. 2, 2016. Disponível em: http://www.cadernos.cenpec.org.br/cadernos/ index.php/cadernos/article/ view/361. Acesso em: 18 abr. 2020.

\section{João Batista da Silva}

Doutorando em Educação pela Universidade Estadual do Ceará (UECE). Mestre em Ensino de Ciências e Matemática pelo Programa de Pós-Graduação em Ensino de Ciências e Matemática (PGECM/IFCE). Especialista em ensino de Física pela Universidade Candido Mendes (UCAM). Graduado em Licenciatura em Física pelo Instituto Federal de Educação, Ciência e Tecnologia do Ceará (IFCE).

Email: joaobathista82@hotmail.com

\section{Patrícia Félix Duarte}

Mestranda em Educação pela Universidade Estadual do Ceará (UECE). Email: pati.felix@gmail.com 


\section{Aline de Oliveira Rebouças}

Mestranda em Educação pela Universidade Estadual do Ceará (UECE). Email: aline.reboucas@aluno.uece.br

\section{Eloísa Maia Vidal}

Doutora em Educação pela Universidade Federal do Ceará (UFC). Professora Associada do Departamento de Física da Universidade Estadual do Ceará (UECE). Email: eloisamvidal@yahoo.com.br

Recebido em: 24/04/2020

Aprovado em: 07/09/2020 